\title{
AN EXAMPLE OF POLYPLOIDY IN PIG BLASTOCYSTS *
}

\author{
R. G. MOON, M. N. RASHAD AND M. P. MI \\ Pig Research Institute, Chunan, Taiwan, Republic of China, and \\ Department of Genetics, University of Hawaii, Honolulu, Hawaii 96822, U.S.A.
}

\section{(Received 4th February 1975)}

Cytogenetic data on mammalian preimplantation zygotes are limited. Blastocysts of pigs, rabbits and mice have been described as having chromosome abnormalities. Most of the reported abnormalities in mammalian blastocysts were triploid and tetraploid (Shaver \& Carr, 1967, 1969; McFeely, 1967; Fechheimer \& Beatty, 1974). Two instances of hexaploidy were found in mice (Beatty, 1957). In rabbits, one pentaploid and octaploidy in two mixoploids $(2 n / 4 n / 8 n)$ were found by Shaver \& Garr (1967).

This communication describes an observation of polyploidy in pig blastocysts. A 5-year-old Landrace $\times$ Large White crossbred sow which had produced a total of eleven litters was available for study. She had first conceived at 12 months of age, but produced four mummified fetuses (due to Japanese encephalitis) after 100 days of pregnancy. All subsequent pregnancies were normal with an average number of 8.3 livebirths and 1.3 stillbirths per litter. The last litter was weaned at 28 days of age; the sow became oestrous 3 days later. Artificial insemination was performed with $50 \mathrm{ml}$ fresh semen from a Duroc boar on the first day of oestrus and a second insemination was performed $24 \mathrm{hr}$ later with the same semen that had been preserved in a skimmilk-glucose diluent at $15^{\circ} \mathrm{C}$.

On the 11 th day after insemination, the sow was slaughtered and the cervix, uterus, oviducts and ovaries were removed as a unit. The number of corpora lutea (47) was counted and used as the criterion for the number of ova produced. The mesometrium was cut away and the uterus was bisected so that the coiled uterine horns would be extended independently. The uterus was then suspended vertically by the cervical end and a funnel was introduced through the canal into the cavity of the uterus. The uterine horns were bisected at the junction of the oviducts; $200 \mathrm{ml}$ Hanks' medium were poured through the uterus, flushing the blastocysts into a beaker at the tubal extremity.

Forty-one blastocysts were recovered and appeared healthy. They were allocated arbitrarily into five groups for chromosome preparation to establish a consistent technique (Table 1). Of fifteen blastocysts, four had abnormal karyotypes: one was tetraploid and three were mixoploid, namely, $2 n / 4 n, 2 n / 6 n$ and $2 n / 32 n$ (Pl. 1, Figs 1 and 2). All blastocysts were similar in size measuring 4 to $5 \mathrm{~mm}$ in diameter with the exception of four which had diameters of only 1 to $2 \mathrm{~mm}$. Of these four smaller blastocysts, one was tetraploid, two normal and one did not yield results.

* Reprint requests to: Dr M. P. Mi, Pig Research Institute, Chunan, Taiwan, Republic of China. 
McFeely (1967) studied 88 blastocysts collected from seven gilts sired by unrelated boars, 10 days after insemination. Of these, chromosome abnormalities were found in nine blastocysts: four were triploid, three were tetraploid, one was mixoploid $(2 n / 3 n)$ and one had a structural anomaly.

In rabbits, Shaver \& Carr (1967) found 13/135 blastocysts with chromosome abnormalities: six triploid, three were mixoploid, one pentaploid, one trisomic, one mosaic, and one had a structural anomaly.

Table 1. The treatment and ploidy of blastocysts from one sow

\begin{tabular}{|c|c|c|c|c|c|}
\hline Group & Treatment & $\begin{array}{c}\text { No. of } \\
\text { blastocysts }\end{array}$ & $\begin{array}{c}\text { Successful } \\
\text { preparations }\end{array}$ & Diploid & Polyploid \\
\hline 1 & Direct (McFeely, 1966) & 9 & 2 & 2 & - \\
\hline 2 & Direct without colcemid & 6 & 2 & 2 & - \\
\hline 3 & 1 day, Eagles medium & 10 & 8 & 4 & 4 \\
\hline 4 & 2 days, Eagles medium & 6 & 2 & 2 & - \\
\hline \multirow[t]{2}{*}{5} & 8 days, Eagles medium & 10 & 1 & 1 & - \\
\hline & Total & 41 & 15 & 11 & 4 \\
\hline
\end{tabular}

Colcemid $0 \cdot 1 \mu \mathrm{g} / \mathrm{ml}$ was added $1 \frac{1}{2} \mathrm{hr}$ before harvesting. Eagles MEM (GIBCO) supplemented with $10 \%$ fetal calf serum (GIBCO).

Blastocysts recovered from mice induced to superovulate were studied by Vickers (1967): of 115, four were abnormal, one was haploid, one trisomic and two had structural abnormalities. While 36 chromosomally normal blastocysts were recovered from control rabbits that were not induced to superovulate, Fujimoto et al. (1974) reported 7/72 rabbit blastocysts with abnormal chromosomes: three were triploid, one mosaic, one trisomic, one monosomic and one with sex chromosome chimaerism. Fechheimer \& Beatty (1974) analysed 463 blastocysts from rabbits induced to superovulate and found 23 to be heteroploid. They comprised eight triploids, four trisomics, four diploid/trisomic mosaics, one diploid/monosomic mosaic, four diploid/tetraploid mosaics, one diploid/ triploid mosaic and one triploid/hexaploid mosaic.

Delayed fertilization has been shown to be associated with polyploidy. Austin \& Braden (1953) found a great increase in polyspermy associated with delayed mating in the rat. Shaver \& Carr $(1967,1969)$ showed that delayed mating in the rabbit after induction of ovulation increased the proportion of triploid blastocysts. Day \& Polge (1968) reported increased polyspermy in the pig when the ova were aged. However, Fechheimer \& Beatty (1974) reported findings which indicate that diploid spermatozoa were not a major cause of triploidy among rabbit embryos.

The cause and significance of the hexaploidy and $32 n$ in the pig blastocysts described in the present study remains unknown.

This work was supported in part by grants from the Joint Commission on Rural Reconstruction, National Science Council, Taiwan, and U.S. Public Health Service, HD 00400. The authors are indebted to Dr Ann M. Budy, University of Hawaii, Pacific Biomedical Research Center, for helpful discussions and collaborative efforts. 


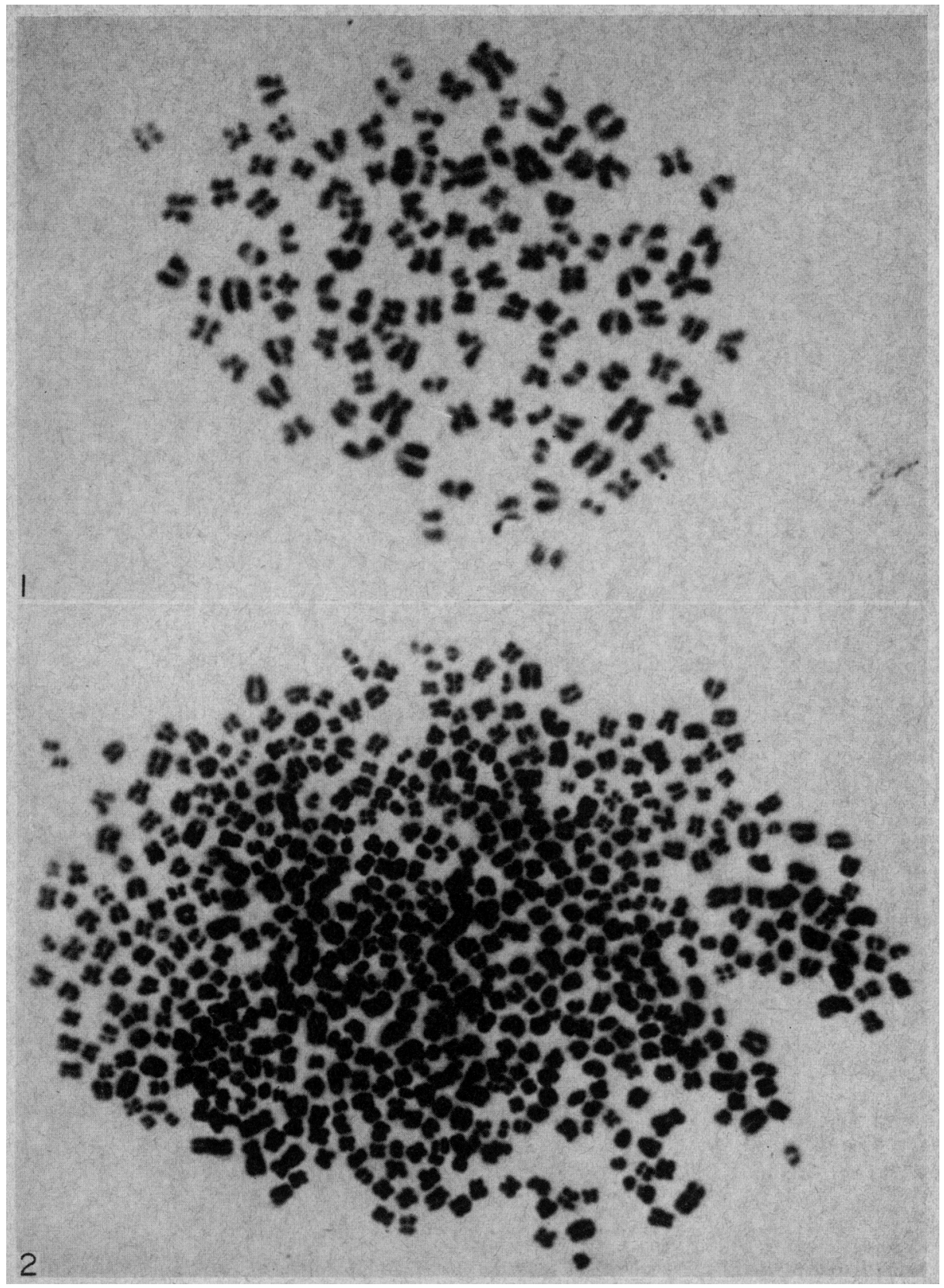

Fig. 1. Hexaploid cell from a pig blastocyst.

FIG. 2. Polyploid (32n) cell from a pig blastocyst.

(Facing p. 148) 


\section{REFERENCES}

Austin, G.R. \& Braden, A.W.H. (1953) An investigation of polyspermy in rat and rabbit. Aust. F. biol. Sci. 6, 674-692.

Beatty, R.A. (1957) Parthenogenesis and Polyploidy in Mammalian Development. Cambridge University Press, London.

Day, B.N. \& PolgE, C. (1968) Effects of progesterone on fertilization and egg transport in the pig. 7. Reprod. Fert. 17, 227-230.

FeGHHeimer, N.S. \& BeATTY, R.A. (1974) Chromosomal abnormalities and sex ratio in rabbit blastocysts. F. Reprod. Fert. 37, 331-341.

Fujimoto, S., Pahlavan, N. \& Dukelow, W.R. (1974) Chromosome abnormalities in rabbit preimplantation blastocysts induced by superovulation. F. Reprod. Fert. 40, 177-181.

MaFeELY, R.A. (1966) A direct method for the display of chromosomes from early pig embryos. 7. Reprod. Fert. 11, 161-163.

MCFEeLy, R.A. (1967) Chromosome anomalies in early embryos of the pig. F. Reprod. Fert. 13, 579-581.

SHAver, E.L. \& CARR, D.H. (1967) Chromosome abnormalities in rabbit blastocysts following delayed fertilization. 7. Reprod. Fert. 14, 415-420.

Shaver, E.L. \& CARR, D.H. (1969) The chromosome complement of rabbit blastocysts in relation to the time of mating and ovulation. Can. F. Genet. Cytol, 11, 287-293.

Vickers, A.D. (1967) A direct measurement of the sex ratio in mouse blastocysts. F. Reprod. Fert. 13, 375-376. 